\title{
Blood-nourishing and Hard-softening Capsule Costs Less in the Management of Osteoarthritic Knee Pain: A Randomized Controlled Trial
}

\author{
Yuelong Cao ${ }^{1}$, Yinyu Shi ${ }^{1}$, Yuxing Zheng ${ }^{1}$, Meiyu Shi ${ }^{1}$ and Sing Kai Lo ${ }^{1,2}$ \\ ${ }^{1}$ Research Institute of Orthopaedics and Traumatology, Shanghai University of Traditional Chinese Medicine, \\ Shanghai, China and ${ }^{2}$ Faculty of Health and Behavioural Sciences, Deakin University, Melbourne, Australia
}

\begin{abstract}
The blood-nourishing and hard-softening (BNHS) capsule is a traditional Chinese formula used in the symptomatic treatment of inflammation and pain. We conducted this randomized controlled trial to compare the efficacy of BNHS with other commonly prescribed drugs. We recruited 120 patients from two teaching hospitals; 30 patients in each hospital were randomly assigned to receive BNHS. In one hospital, the 30 controls were given another traditional Chinese drug; whereas a Western medicine (chondroprotection drug/Viartril-s) was used as the control in the other hospital. Intervention was carried out over a period of 4 weeks. Primary outcome measures included self-reported pain level, and changes in stiffness and functional ability as measured by the Western Ontario McMaster Universities Osteoarthritis (WOMAC) index. Mixed models were used for statistical analysis. Substantial improvements in disease-specific symptoms were observed, after 4 weeks of treatment, in patients taking BNHS capsules. As assessed by the WOMAC index, pain level of the BNHS group decreased by $57 \%$ [95\% confidence interval $(\mathrm{CI})=50,63]$, stiffness by $63 \%(95 \% \mathrm{CI}=55,71)$ and functional ability increased by $56 \%$ $(95 \% \mathrm{CI}=50,63)$. No significant differences were found in any of the outcome measures between the BNHS group and either of the comparison groups. No severe adverse effects were reported. However, this study lacked a placebo group; therefore, we conclude that BNHS appears to be as effective as commonly prescribed medicines for the relief of pain and dysfunction in knee osteoarthritis patients, but costs a lot less than other Western and herbal drugs in the study.
\end{abstract}

Keywords: Chinese herbal medicine - chondroprotection drug - WOMAC

\section{Introduction}

Osteoarthritis (OA) is the most common joint disease. Clinical manifestations of $\mathrm{OA}$ of the knee are joint pain, stiffness in the morning or after rest, pain at night, limited joint motion and/or joint deformity (1). Treatment modalities for knee OA include non-pharmacologic (e.g. physical and occupational therapy, aerobic exercise programs, weight control and patient education) and pharmacologic therapy [e.g. intra-articular steroid injections, paracetamol, topical analgesics, non-steroidal

For reprints and all correspondence: Professor Sing Kai Lo, Faculty of Health and Behavioural Sciences, Deakin University, 221 Burwood Highway,

Burwood, VIC 3125, Australia. Tel: +61-3-9251-7314;

Fax: +61-3-9244-6261; E-mail: singkai.lo@ deakin.edu.au anti-inflammatory drugs (NSAIDs) and opioid analgesics] (2). Although NSAIDs are the most widely prescribed drugs to reduce joint pain and stiffness, the inflammatory component of OA is usually minimal; therefore, the need for the anti-inflammatory effect of NSAIDs in this condition is controversial (3). Since the efficacy of NSAIDs in symptomatic treatment of OA of the knee depends on analgesic rather than anti-inflammatory effect, paracetamol has been recently recommended as the first-line oral drug. On the one hand, long-term use of paracetamol can lead to hepatic and renal impairment (4). On the other hand, inhibition of prostaglandin biosynthesis is directly related to many common and occasionally severe side effects including gastrointestinal bleeding, hypertension, congestive heart failure, hyperkalemia and renal

(C) The Author (2005). Published by Oxford University Press. All rights reserved.

The online version of this article has been published under an open access model. Users are entitled to use, reproduce, disseminate, or display the open access version of this article for non-commercial purposes provided that: the original authorship is properly and fully attributed; the Journal and Oxford University Press are attributed as the original place of publication with the correct citation details given; if an article is subsequently reproduced or disseminated not in its entirety but only in part or as a derivative work this must be clearly indicated. For commercial re-use, please contact journals.permissions@oupjournals.org 
insufficiency $(5,6)$. These disadvantages call for an evaluation of the risks and benefits of the therapies in comparison with a less toxic one for OA. Thus, less toxic pain managing procedures, e.g. electroacupuncture or acupuncture as reported, as well as chondroprotection drugs are considered alternative treatments and they are widely prescribed in China.

Evidence gathered from a systematic review show that herbal medicines, which appear relatively safe, may offer a much-needed alternative, and merit further attention (7). The blood-nourishing and hard-softening capsule (BNHS), which is an extract from Bai Shao (radix paeoniae alba), Qin Jiao (radix gentianae macrophyllae) and Gan Cao (radix glycyrrhizae), containing mainly paconiflorin and gentianine, is a traditional Chinese herb used for symptomatic treatment of inflammation and pain in OA. In traditional Chinese medicine (TCM), OA is known as the Bi syndrome (painful obstruction), which means either the limbs or the joints are suffered from pain and malfunction, and herb therapy has long been a standard treatment. Only limited data are available on the efficacy and cost-effectiveness of traditional Chinese herbs in the treatment of OA of the knee. Therefore, we initiated this study to compare the efficacy of BNHS, another commonly prescribed Chinese herb counter osteophytes capsule, and Western medicine Viartril-s (chondroprotection drug) in short-term symptomatic treatment of OA of the knee. We hypothesized that BNHS is as effective as, but will cost less than, other commonly prescribed drugs chosen for comparison purposes.

\section{Materials and Methods}

\section{Study Design}

This was a prospective two-center randomized controlled trial. All patients underwent a treatment period of 4 weeks, and followed for $\geq 2$ weeks to check for adverse events. The protocol was approved by the Ethics Committee of the University in Shanghai. The trial was conducted under the Good Clinical Practice (GCP) guidelines. All patients gave informed written consent.

\section{Patients}

We screened all outpatients, aged $\geq 50$, who in 2002 attended the Department of Orthopaedics in two teaching hospitals in Shanghai. All of them suffered from painful OA of the knee according to American College of Rheumatology criteria (8). Additional inclusion criteria were as follows: intake of NSAIDs for at least 5 days before the study entry, but presented with adverse events from previous NSAID therapy; had pain intensity of $\geq 20 \mathrm{~mm}$ on the visual analog scales (VASs) in the previous $48 \mathrm{~h}$ when walking on a flat surface; radiological evidence of $\mathrm{OA}$ in the painful joint; at least grades II-IV on the Kellgren-Lawrence scale on an X-ray taken within 12 months; and reluctant to continue on previous drug but willing to change drug treatment. Exclusion criteria include concurrent medical/arthritic diseases such as secondary inflammatory arthritis, gout, episodes of acute monoarticular arthritis, isolated patellofemoral disease, a history of acute ligamentous or meniscal injury of the study joint within the previous 2 years and arthroscopy of the affected knee in the 3 months before the study entry, which could confound or interfere with the evaluation of efficacy. Subjects with hypersensitivity to one of the ingredients of the BNHS or rescue medication, asthma attacks, episodes of urticaria or acute rhinitis after administration of aspirin or other NSAIDs were not included in the study. Patients with severe heart, renal or liver insufficiency including increased liver function tests, blood urea nitrogen test, alanine aminotransferase test and other biochemistry tests three times higher than the upper limit of normal range, or with acute or suspected gastrointestinal bleeding, active gastric or duodenal ulcer, ulcer diagnosed endoscopically within the previous 28 days, steroid injection $<3$ months were also excluded.

\section{Procedures}

A total of 120 patients, 60 in each hospital, were recruited from eligible patients. They were randomly (using the sealed envelope method) and blindly assigned to treatment (BNHS) or control care (counter osteophytes capsule, another traditional Chinese drug) in Hospital A. Since Hospital B used Western medicine (Viartril-s, a chondroprotection drug) as control care, and there are pharmacokinetical differences between Chinese and Western medicine, we could only blind the clinician who performed the assessments.

On Day 0 (Visit 1), patients stopped their previous NSAID therapy and started taking either BNHS (Experimental) or counter osteophytes capsule (Control 1) or Viartril-s capsule (Control 2) with a daily dose of 3.15, 5.25 and $2.25 \mathrm{~g}$, respectively. On Day 14 patients returned for an interim visit (Visit 2). On Day 28 the final visit took place (Visit 3). Thus, the duration of treatment was 4 weeks. Two weeks after Visit 3 or after discontinuation the patient was contacted to check for adverse events.

As a pain rescue medication, patients were allowed to take paracetamol $500 \mathrm{mg}$ on demand, e.g. in the event of breakthrough pain, with a maximum dose of $4 \mathrm{~g} \mathrm{day}^{-1}$. We counted and recorded all returned tablets at each visit. There were no study-specific restrictions with regard to previous and concomitant medication and treatments, except that co-administration of NSAIDs was not allowed during the study period. Low-dose aspirin $\left(<100 \mathrm{mg} \mathrm{d}^{-1}\right)$ was allowed, provided the dosage was not changed during the study period and had been stable for months.

\section{Clinical Endpoints and Outcome Measures}

The endpoints used for the study included pain when walking on a flat surface, pain, stiffness and functional ability. To be specific, the radiological severity of OA was assessed at Day 0 using the Kellgren-Lawrence index. At each visit (Days 0, 14 and 28) the patients were rested in a sitting position 
for $10 \mathrm{~min}$ before monitoring the vital signs. They were also asked to complete the following questionnaires: (i) patient's global assessment of treatment satisfaction (5-point scale; $0=$ poor, $4=$ excellent); (ii) patient's assessment of pain when walking on a flat surface (VAS; $0=$ no pain, $100=$ major pain) (9); (iii) Western Ontario McMaster Universities Osteoarthritis (WOMAC) LK 3.1; and (iv) global assessment of treatment response (5-point scale; $0=$ very well, $4=$ very very poor) completed by the same investigator (Y.C.).

\section{Tolerability and Safety}

Spontaneously reported adverse events were recorded throughout the study. Vital signs were monitored at every visit. Laboratory investigations including hematology, blood chemistry and urinalysis were performed at Days 0 and 28, and repeated on a need basis. For all adverse events the intensity, relation to test drug and actions taken were recorded.

\section{Statistical Analysis}

Data analysis was performed according to the intention-totreat (last observation carried forward) principle using SPSS V12.0. Mixed models, treating group as the between-subject factor and time as the within-subject factor, were formulated to compare outcome scores between groups and over time. When significant interaction between group and time was detected, analysis of covariance was used to compare groups at Days 14 and 28 after adjusted for baseline values. While the overall significance level was set at 0.05 , the Sharpened Bonferroni procedure (10) was used to adjust individual alpha level when multiple testing was performed.

\section{Results}

In the two hospitals, 136 patients were approached before 120 agreed to participate. The primary diagnosis was knee OA. The radiological Kellgren-Lawrence index was II (slight OA) in $22.5 \%$ of the patients and III (moderate OA) or IV (major OA) in 54.2 and $23.3 \%$, respectively. One hundred sixteen subjects completed the study per protocol (three experienced adverse events and one refused to take the study drug, all after Visit 2), but analyses were carried out using all the 120 patients ('last observation carried forward' for the four 'incomplete' patients). One-third of the randomized participants were males and the mean age was $69(\mathrm{SD}=8)$ years. No significant differences in mean age or gender ratios were observed between the BNHS and the control groups (Table 1).

\section{WOMAC}

As assessed by the WOMAC index, pain decreased by $57 \%$ [95\% confidence interval $(\mathrm{CI})=50,63 ; P<0.001$ ], stiffness by $63 \%(95 \% \mathrm{CI}=55,71 ; P<0.001)$ and functional ability increased by $56 \%(95 \% \mathrm{CI}=50,63 ; P<0.001)$ over the course (i.e. 4 weeks) of the study in BNHS patients. As shown in Tables 2-4, the improvement from Days 14 to 28 (percent improvement varied from 33 to $51 \%$ depending on the outcome measure and Hospital) was substantially more than that from baseline to Week 2 (percent improvement varied from 23 to $32 \%$ ), although statistical significance was not reached in some outcome measures among patients in Hospital A.

However, for the sample size we had, we found no significant differences in the pattern of change from baseline to Day 28 between the treatment and the control groups, regardless of whether the control was TCM herb or Western medicine, as none of the interaction terms were significant.

We also noted that although most of the WOMAC scores (except pain) were significantly different between patients in the three treatment regimes (i.e. BNHS, Chinese herb control and Western medicine control) at Day 0, the scores were very similar at Day 28. This seems to suggest that regardless of the initial clinical situation of the patient, there is a threshold such that once the limit is reached the patient cannot improve further, at least for the drugs used in this study and after 4 weeks of treatment.

\section{Other Outcome Measures}

The outcome measures also included assessment of pain when walking on a flat surface, investigator's global assessment of treatment response as well as patient's global assessment of treatment satisfaction. The results are shown in Tables 3 and 4. By and large, none of these outcome measures were significantly different between the BNHS and the control groups. The patterns of the results for pain when walking on a flat surface, whether it was the change from baseline to Weeks 2 or 4, or the absolute scores obtained at end of study, were very similar to those of the WOMAC scores. However, patients in the BNHS group in Hospital A appeared to be slightly more satisfied than the controls (Good/Excellent: 50 versus $30 \% ; P=0.095$ ), although the differences were marginally non-significant.

Table 1. Baseline characteristics of the participants

\begin{tabular}{|c|c|c|c|c|c|c|}
\hline & \multicolumn{3}{|c|}{ Hospital A (Chinese medicine control) } & \multicolumn{3}{|c|}{ Hospital B (Western medicine control) } \\
\hline & $\mathrm{BNHS}^{*}(n=30)$ & $\begin{array}{l}\text { Counter osteophytes } \\
\text { capsule }(n=30)\end{array}$ & $P$-value & BNHS* $(n=30)$ & Viartril-s $(n=30)$ & $P$-value \\
\hline Age (years) & $59 \pm 7$ & $60 \pm 10$ & 0.612 & $64 \pm 9$ & $62 \pm 9$ & 0.282 \\
\hline Female gender & $22(73.3 \%)$ & $17(56.7 \%)$ & 0.176 & $24(80.0 \%)$ & $17(56.7 \%)$ & 0.052 \\
\hline Disease duration (years) & $11 \pm 8$ & $10 \pm 8$ & 0.829 & $10 \pm 8$ & $11 \pm 8$ & 0.828 \\
\hline
\end{tabular}

*BNHS = blood-nourishing and hard-softening capsule. 
Table 2. Comparison of WOMAC scores between the treatment groups

\begin{tabular}{|c|c|c|c|c|c|c|c|c|c|}
\hline & Baseline $^{\dagger}$ & 2 weeks & 4 weeks & $\begin{array}{l}\text { Percent changed } \\
\text { from baseline } \\
\text { to } 4 \text { weeks }\end{array}$ & Baseline & 2 weeks & 4 weeks & $\begin{array}{l}\text { Percent changed } \\
\text { from baseline } \\
\text { to } 4 \text { weeks }\end{array}$ & $P$-value \\
\hline Hospital A & & \multicolumn{3}{|c|}{ BNHS $(n=30)$} & \multicolumn{4}{|c|}{ Counter osteophytes capsule $(n=30)$} & \\
\hline Pain $^{\S}(\%$ changed $)$ & $28 \pm 17$ & $21 \pm 13(27)$ & $14 \pm 12(33)$ & 50 & $29 \pm 11$ & $21 \pm 11(28)$ & $15 \pm 9(29)$ & 48 & 0.753 \\
\hline Stiffness $^{\S}(\%$ changed $)$ & $26 \pm 19$ & $18 \pm 17(23)$ & $12 \pm 14(46)^{*}$ & 54 & $27 \pm 21$ & $20 \pm 18(26)$ & $15 \pm 16(25)$ & 44 & 0.669 \\
\hline $\operatorname{Total}^{\S}$ ( $\%$ changed $)$ & $32 \pm 4$ & $22 \pm 4(32)$ & $12 \pm 5(45)^{* *}$ & 63 & $34 \pm 6$ & $23 \pm 5(32)$ & $13 \pm 5(43)$ & 62 & 0.208 \\
\hline Pain $^{\S}(\%$ changed $)$ & $29 \pm 5$ & $20 \pm 4(30)$ & $11 \pm 5(46)^{* *}$ & 62 & $34 \pm 8$ & $24 \pm 7(29)$ & $14 \pm 7(42)$ & 59 & 0.288 \\
\hline Stiffness $^{\S}(\%$ changed $)$ & $33 \pm 9$ & $22 \pm 7(33)$ & $11 \pm 6(51)^{* *}$ & 67 & $38 \pm 9$ & $26 \pm 8(32)$ & $14 \pm 7(46)$ & 63 & 0.318 \\
\hline Disability $^{\S}(\%$ changed $)$ & $32 \pm 4$ & $22 \pm 4(32)$ & $12 \pm 5(44)^{* *}$ & 63 & $33 \pm 6$ & $22 \pm 5(33)$ & $12 \pm 5(45)$ & 64 & 0.200 \\
\hline
\end{tabular}

${ }^{\dagger}$ No significant differences between the two groups at baseline in any of the measurements.

${ }^{\ddagger} P$-value for group by time interaction, i.e. testing whether the change from baseline to 4 weeks was different between the two groups or not.

${ }^{\S}$ Percent changed from the previous time period.

$* P<0.05$.

**P $P<0.01$ as compared with the changed from baseline to Week 2 (analysis for BNHS only).

Table 3. Comparison of other outcome measures between the groups: pain when walking on a flat surface

\begin{tabular}{|c|c|c|c|c|c|c|c|c|c|}
\hline & Baseline $^{\dagger}$ & 2 weeks & 4 weeks & $\begin{array}{l}\text { Percent changed } \\
\text { from baseline } \\
\text { to } 4 \text { weeks }\end{array}$ & Baseline & 2 weeks & 4 weeks & $\begin{array}{l}\text { Percent changed } \\
\text { from baseline } \\
\text { to } 4 \text { weeks }\end{array}$ & $P$-value ${ }^{\ddagger}$ \\
\hline Hospital A & & \multicolumn{3}{|c|}{ BNHS $(n=30)$} & \multicolumn{4}{|c|}{ Counter osteophytes capsule $(n=30)$} & \\
\hline Hospital B & & \multicolumn{3}{|c|}{ BNHS $(n=30)$} & \multicolumn{4}{|c|}{ Viartril-s $(n=30)$} & \\
\hline $\begin{array}{l}\text { Pain }(\mathrm{VAS})^{\S} \\
(\% \text { changed })\end{array}$ & $47 \pm 10$ & $31 \pm 9(36)$ & $18 \pm 9(44)^{* *}$ & 62 & $51 \pm 14$ & $35 \pm 11(31)$ & $20 \pm 10(43)$ & 61 & 0.536 \\
\hline
\end{tabular}

${ }^{\dagger}$ No significant differences between the two groups at baseline in any of the measurements.

${ }^{\ddagger} P$-value for group by time interaction, i.e. testing whether the change from baseline to 4 weeks was different between the two groups or not.

${ }^{\S}$ Percent changed from the previous time period.

$* P<0.05$.

**P $P<0.01$ as compared with the changed from baseline to Week 2 (analysis for BNHS only).

Table 4. Comparison of other outcome measures between the groups: patient satisfaction and investigator's assessment of treatment response

\begin{tabular}{|c|c|c|c|c|c|c|}
\hline & \multicolumn{3}{|c|}{ Patient satisfaction } & \multicolumn{3}{|c|}{ Investigator's assessment of treatment response } \\
\hline & BNHS $(n=30)$ & Control $(n=30)$ & $P$-value* & BNHS $(n=30)$ & Control $(n=30)$ & $P$-value* \\
\hline \multicolumn{7}{|l|}{ Hospital A } \\
\hline Fair $(\%)$ & 36.7 & 60.0 & & 36.7 & 50.0 & \\
\hline Good $(\%)$ & 30.0 & 6.7 & & 33.3 & 26.7 & \\
\hline Excellent (\%) & 20.0 & 23.3 & & 16.7 & 13.3 & \\
\hline Poor $(\%)$ & 0 & 0 & 0.935 & 0 & 0 & 0.580 \\
\hline Fair $(\%)$ & 16.7 & 20.0 & & 23.3 & 16.7 & \\
\hline Good $(\%)$ & 43.3 & 43.3 & & 50.0 & 63.3 & \\
\hline Excellent $(\%)$ & 40.0 & 36.7 & & 26.7 & 20.0 & \\
\hline
\end{tabular}

*P-values comparing BNHS and control within each hospital.

\section{Adverse Events}

One BNHS case in Hospital A had macule that could be related to treatment. Four patients, all in the BNHS group in Hospital A, withdrew from the trial due to obstipation (one case), gum swelling (two cases) and bitter feeling in the mouth (one case). None of these were considered serious by the investigators. No severe adverse cardiovascular events or deep vein thrombosis were observed. No hospitalization or death 
occurred due to adverse events. No adverse events occurred in Hospital B.

\section{Switch Pattern}

In the telephone survey, 2 weeks after completion of the 4 week study, 61\% (35/57) had decided to stay on BNHS capsule and $60 \%(18 / 30)$ on Viartril-s capsule, but only 48\% (14/29) preferred to stay on counter osteophytes capsule; however, the differences were not statistically significant.

\section{Dosage and Cost}

All the 116 subjects who completed the study had a $100 \%$ dose taking record. To be specific, $88.2 \mathrm{~g}$ BNHS, $147 \mathrm{~g}$ counter osteophytes or $63 \mathrm{~g}$ Viartril-s drugs were taken by each patient in the treatment and two control groups, respectively, during the 4 week period. For the dosage used in this study, the cost for BNHS was only $80 \%$ compared with counter osteophytes capsule and $12 \%$ compared with Viartril-s.

\section{Discussion}

This study documents the benefits of treating OA of the knee with BNHS for OA patients who were either unresponsive to or presented with adverse events from previous NSAID therapy. We found that BNHS significantly improved WOMAC pain, stiffness and function over 4 weeks. Although lots of reports show that Chinese herbs are potentially effective in the treatment of OA, few of them were carried out in accordance with the GCP principle. We have followed the GCP guidelines as close as possible when conducting the study.

Previous studies have demonstrated the efficacy of the COX-2 specific NSAIDs in the treatment of pain and inflammation due to OA, as well as its efficacy profile relative to classical (non-COX-2 specific) high-dose NSAIDs (11-14). Other studies have demonstrated the superior safety profile of such drugs compared with classical NSAIDs, with a particular focus on upper gastrointestinal adverse events such as perforation, ulcers and bleeding (15). As COX-2 specific NSAIDs is a relatively new drug, more research, especially long-term follow-ups and examination of adverse effects, are needed before its efficacy is established. Hence, we have not chosen COX-2 specific NSAIDs as the Western control medicine.

Numerous TCM methods have been used in the treatment of OA. The most widely studied method was acupuncture, with several studies examining the short-term and long-term effectiveness of the treatment in relieving clinical pain (16-18). Nevertheless, flaws and limitations in these studies have been reported (19). These included inadequate sessions of treatment, failure to control concomitant therapies and no sham, placebo or controlled group. However, scientific data on the efficacy of herbal formulae in the treatment of OA are rarely available. It was difficult to choose the kind of Chinese medicine for comparison purposes. We finally decided to use a drug that is commonly prescribed.
$\mathrm{OA}$ is a disease in which compliance and persistence are known to be rather poor. In this study, the BNHS was generally safe and well tolerated. After 4 weeks of treatment, $61 \%$ still preferred to stay on BNHS. Compared with NSAIDs, the anti-pain mechanism of BNHS is still unclear. The specific way NSAIDs develop effect is through the inhibition of COX. Meanwhile, the most common renal effects of conventional NSAIDs attributable to the inhibition of COX are a reduction in both glomerular filtration rate and excretion of sodium, with the attendant potential for fluid retention and edema (19). Viartril-s mainly consists of chondroitin sulfate, which is a chondroprotection agent and a key component of the extracellular matrix of cartilage. Studies have documented that glucosamine is absorbed by the gastrointestinal tract with $26 \%$ bioavailability and incorporated into plasma proteins. The supplement has anti-inflammatory properties but not analgesic properties (20). A previous study showed that BNHS could improve pain threshold of rats, and BNHS could inhibit the expression of matrix metalloproteases- 3 of chondrocyte in vitro. BNHS is a complex formula, the effectiveness of which appeared to be comprehensive and similar to chondroprotection or degeneration protection (21). However, the exact mechanism requires further investigations.

The major limitation of the present study was the lack of a placebo group. We cannot rule out the possibility that patients got better despite any treatments they received, especially symptoms in OA often improve with no treatment and undergo a fluctuating course. The lack of any significant differences across the three treatments might well be explained by this. However, as the two comparison drugs were commonly prescribed in the two participating hospitals, including a control arm with, say, paracetamol but without the chosen control drugs would be extremely difficult for the researchers to obtain ethical approval.

The finding that BNHS is as effective as both controlled drugs is itself very encouraging, as it implies that the costeffectiveness of BNHS could be substantially higher. This is due to the fact BNHS is $88 \%$ less expensive than the Western drug Viartril-s. Although BNHS is only marginally cheaper than the other Chinese herbal medicine, the dosage required to achieve similar effects is lower (88.2 versus $147 \mathrm{~g}$ per case), hence the total cost is substantially lower. It must also be mentioned that compared with boiled herbal formula, capsules are more likely to be accepted.

One limitation of this study was that sample size was not very large. Nevertheless, the effect sizes (in terms of mean differences between the Experimental and the Controls divided by the standard deviations, as shown in Table 2) were fairly small, indicating that the non-significant differences could not be explained by sample size alone; there were in fact no apparent differences in any of the outcome measures between the groups. Yet, any conclusive remarks on equivalence can only be made after a proper bioequivalence study with a much larger sample is conducted. Another limitation was the lack of long-term follow-up and evaluation. However, the duration chosen in the present study was in line with acute 
OA flare episodes, and the study was long enough to document BNHS's rapid onset of action and its sustained efficacy over 4 weeks. Although WOMAC is an internationally recognized measurement method, it has never been used as an outcome measure in clinical trials of Chinese herbs; but we do not see why it could have caused any concerns. Given the differences between Chinese herbs and Western medicine, it was difficult to employ a double-blind design in Hospital B. Unfortunately, the degree of potential bias introduced was simply not estimable.

In conclusion, this study suggests that BNHS improves disease-specific symptoms, such as pain, stiffness and decreased function in patients with painful knee OA within 4 weeks, and has similar effects compared with other commonly prescribed Western and Chinese herbal drugs, but the prescription costs less.

\section{Acknowledgements}

This study was supported by a grant from the Science and Technology Committee, Shanghai, People's Republic of China (No. 014319403).

\section{References}

1. Altman RD, Hochberg MC. Degenerative joint disease. Clin Rheum Dis 1983;9:681-9.

2. Hochberg MC, Altman RD, Brandt KD, Clark BM, Dieppe PA, Griffin MR, et al. Guidelines for the medical management of osteoarthritis. Part II. Osteoarthritis of the knee. American College of Rheumatology. Arthritis Rheum 1995;38:1541-6.

3. Bradley JD, Brandt KD, Katz BP, Kalasinski LA, Ryan SI. Comparison of anti-inflammatory dose of ibuprofen, an analgesic dose of ibuprofen, and acetaminophen in the treatment of patients with osteoarthritis of the knee. N Engl J Med 1991;325:87-91.

4. Buckalew VM,Jr. Habitual use of acetaminophen as a risk factor for chronic renal failure: a comparison with phenacein. Am J Kidney Dis 1996;28:7-13.

5. Griffin MR, Piper JM, Daugherty JR, Snowden M, Ray WA. Nonsteroidal anti-inflammatory drug use and increased risk for peptic ulcer disease in elderly persons. Ann Intern Med 1991;114:257-63.
6. Soll AH, Weinstein WM, Kurata J, McCarthy D. Nonsteroidal antiinflammatory drugs and peptic ulcer disease. Ann Intern Med 1991;114: 307-19.

7. Long L, Soeken K, Ernst E. Herbal medicines for the treatment of osteoarthritis: a systematic review. J Rheumatol 2001;40:779-93.

8. Altman R, Asch E, Bloch D, Bole G, Borenstein D, Brandt K, et al. Development of criteria for the classification and reporting of osteoarthritis: classification of OA of the knee. Arthritis Rheum 1986;29: $1039-49$.

9. Bellamy N, Buchanan WW, Goldsmith CH, Campbell J, Stitt LW. Validation study of WOMAC: a health status instrument for measuring clinically important patient relevant outcomes, to antirheumatic drug therapy in patients with osteoarthritis of the hip or knee. J Rheumatol 1988; $15: 1833-40$.

10. Hochberg Y, Benjamini Y. More powerful procedure for multiple significance testing. Stat Med 1990;9:811-8.

11. Scott LJ, Lamb HM. Rofecoxib. Drugs 1999;58:499-505.

12. Day R, Morrison B, Luza A, Castaneda O, Strusberg A, Helgetveit KB, et al. A randomized trial of the efficacy and tolerability of the COX-2 inhibitor rofecoxib vs. ibuprofen in patients with osteoarthritis. Arch Intern Med 2000;160:1781-7.

13. Saag K, van der Heijde D, Fisher C, Samara A, De Tora L, Bolognese J, et al. Rofecoxib, a new cyclooxygenase 2 inhibitor, shows sustained efficacy, comparable with other non-steroidal anti-inflammatory drugs: a 6-week and a 1-year trial in patients with osteoarthritis. Osteoarthritis Studies Group. Arch Fam Med 2000;9:1124-34.

14. Geba GP, Weaver AL, Polis AB, Dixon ME, Schnitzer TJ. Efficacy of Refecoxib, celecoxib, and acetaminophen in osteoarthritis of the knee. J Am Med Assoc 2002;287:64-71.

15. Deeks JJ, Smith LA, Bradley MD. Efficacy, tolerability, and upper gastrointestinal safety of celecoxib for treatment of osteoarthritis and rheumatoid arthritis: systematic review of randomised controlled trials. Br Med J 2002;325:619-23.

16. Berman BM, Singh BB, Lao L, Langenberg P, Li H, Hadhazy V, et al. A randomized trial of acupuncture as an adjunctive therapy in osteoarthritis of the knee. Rheumatology 1999;38:346-54.

17. Takeda W, Wessel J. Acupuncture for the treatment of pain of osteoarthritic knees. Arthritis Care Res 1994;7:118-22.

18. Lao L, Bergman S, Langenberg P, Wong RH, Berman B. Efficacy of Chinese acupuncture on postoperative oral surgery pain. Oral Surg Med Oral Pathol 1995;79:423-8.

19. Berman BM. Clinical applications of acupuncture: an overview of the evidence. J Altern Complement Med 2001;7:S111-8.

20. Brater DC, Harris C, Redfern JS, Gertz BJ. Renal effects of COX-2 selective inhibitors. Am J Nephrol 2001;21:1-15.

21. Cao YL, Shi YY, Wei F, Li ZJ. Experimental study of PGE expression on osteoarthritis treated with YuanGuLi. Chin J Orthop Traumatol 2001;14: 597-8 (Chinese). 


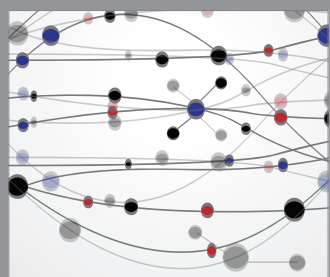

The Scientific World Journal
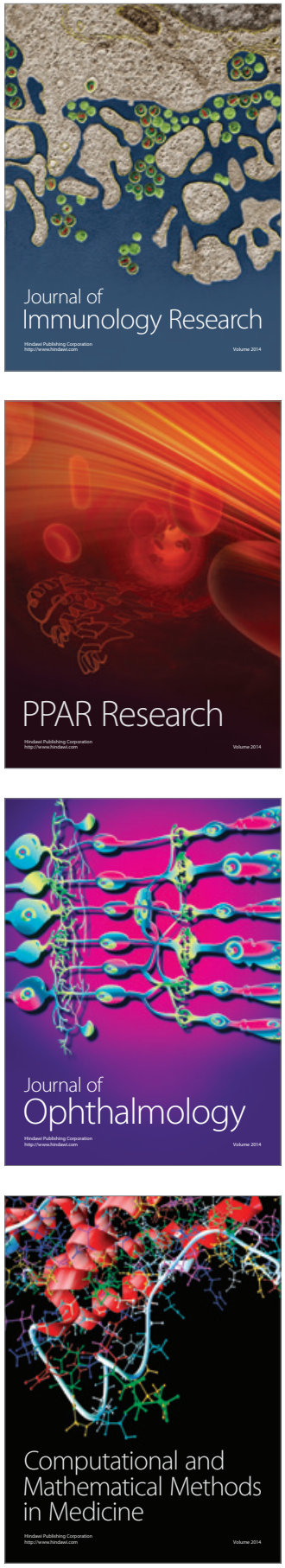

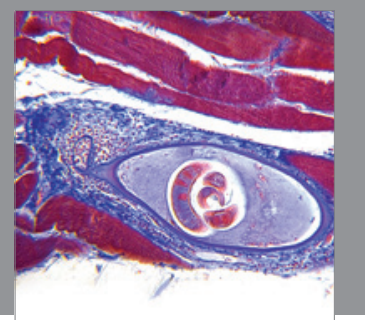

Gastroenterology

Research and Practice
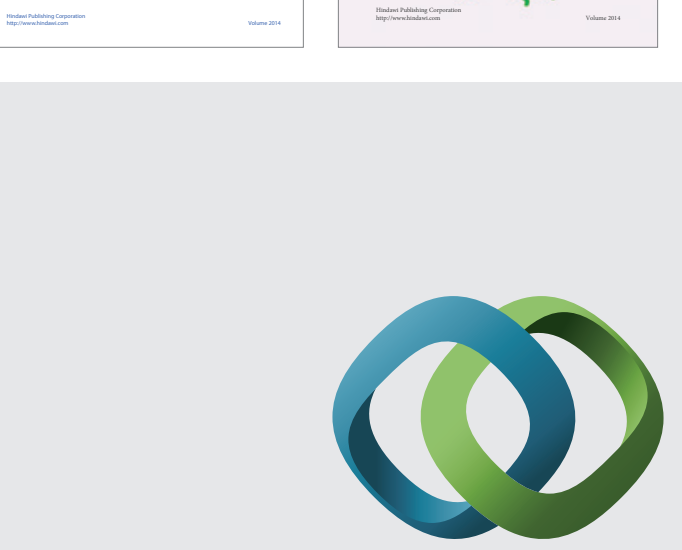

\section{Hindawi}

Submit your manuscripts at

http://www.hindawi.com
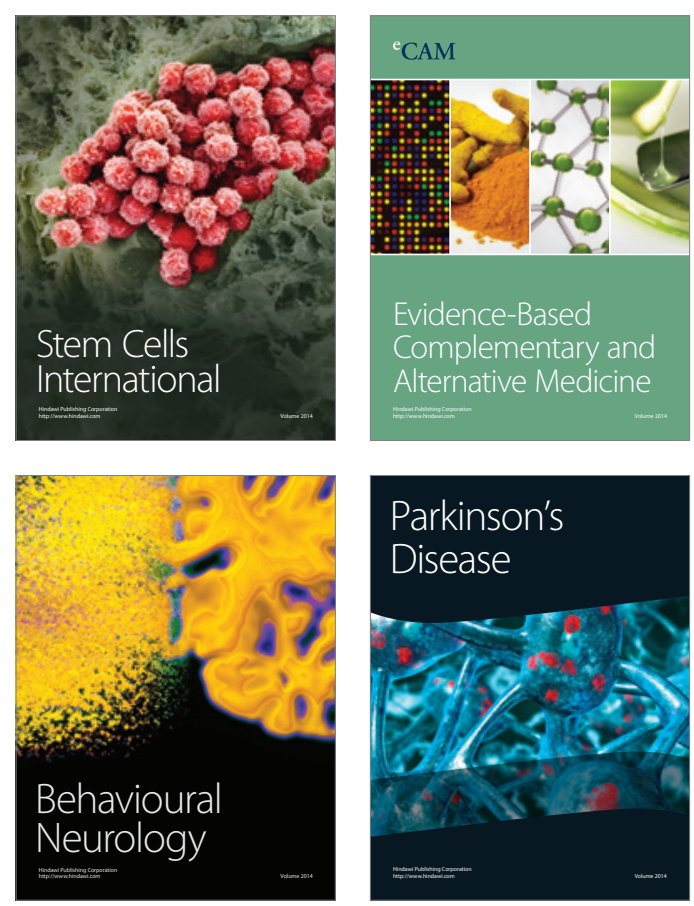

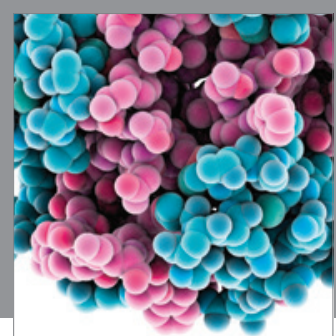

Journal of
Diabetes Research

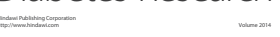

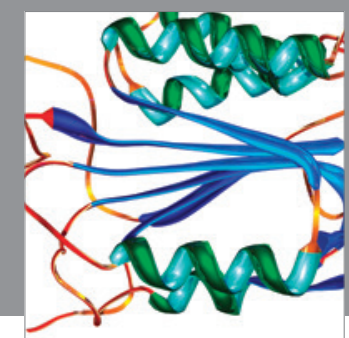

Disease Markers
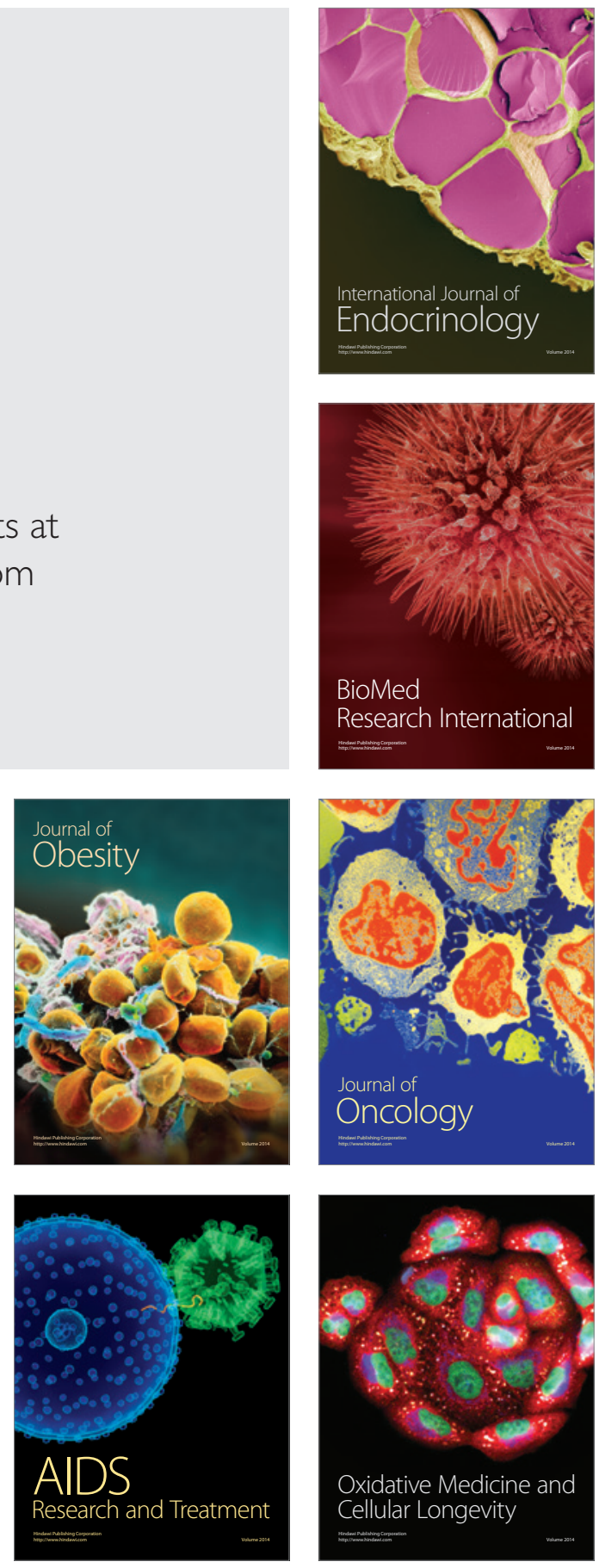